\title{
LA REGULACIÓN DEL DERECHO A LA LIBERTAD DE EXPRESIÓN EN INTERNET: ESTÁNDARES INTERAMERICANOS Y EL CASO DE FACEBOOK
}

\author{
THE REGULATION OF THE FREEDOM OF SPEECH ON THE INTERNET: \\ INTER-AMERICAN STANDARDS AND THE FACEBOOK CASE
}

\author{
Alexandra Cabrera Sánchez ${ }^{1}$ \\ Bachiller en Derecho \\ Universidad de San Martín de Porres \\ cabrerasanchezalexandra@gmail.com
}

Perú

\section{SUMARIO}

- Introducción

- Libertad de expresión

- Libertad de expresión en internet

- Regulación del contenido en internet

- Conclusiones

- Recomendaciones

- Referencias bibliográficas

\section{RESUMEN}

En las siguientes líneas, la autora analiza el derecho a la libertad de expresión, partiendo del marco histórico-conceptual hasta analizar los límites y el desarrollo interamericano de este derecho con la finalidad de analizar su difusión a través de internet mediante los lineamientos reguladores de este derecho en el Sistema Interamericano y en las empresas intermediarias. Finalmente, analiza los vacíos existentes enfocándose en la ausencia del Estado y sus obligaciones de respeto y garantía al permitir un amplio margen de afectación de los derechos fundamentales por medio de la red.

\section{ABSTRACT}

In the following lines the author analyzes the right to freedom of speech, based on the historical and conceptual framework to analyze the limits and Inter-American development of this right in order to analyze its dissemination through internet taking advantage of regulatory guidelines of this right American System and intermediary companies. Finally, it analyzes gaps focusing on the absence of the State and its obligations to respect and guarantee by allowing ample affectation of fundamental rights through the network.

\section{PALABRAS CLAVE}

Libertad de expresión, Sistema Interamericano de Protección de Derechos Humanos, Facebook, libertad de expresión e internet.

\section{KEYWORDS}

Freedom of Speech, Inter-American System of Human Rights Protection, Facebook, freedom of speech and the Internet.

\section{INTRODUCCIÓN}

Es indiscutible la influencia del internet en nuestros días y cómo ha cambiado la sociedad. Sin embargo, aún queda mucho por desarrollar desde la óptica del derecho, toda vez que resulta necesario un control eficaz de los comentarios que se vierten en dicho medio y que pueden afectar los derechos de otras personas.

Este trabajo de investigación tiene como finalidad analizar los alcances de la libertad de expresión en internet y sus límites, analizando específicamente las formas de regular el contenido tanto a nivel de la OEA como de las empresas intermediarias. Nos resulta indispensable analizar la relación entre libertad

1 Investigadora del Centro de Estudios de Derechos Humanos de la Facultad de Derecho de la USMP. 
de expresión e internet, pues usualmente surge la duda de si los estándares desarrollados para la libertad de expresión, a través de otros medios más tradicionales, resultan aplicables también a las expresiones vertidas a través de internet. Ello será comprobado en este trabajo.

En ese sentido, esta investigación parte del marco teórico e histórico del derecho de libertad de expresión para poder llegar a lo regulado también en los instrumentos internacionales. Así que se analizarán los estándares existentes a nivel del Sistema Interamericano, al que pertenecemos como Estado peruano. Ello nos servirá como base para analizar cuáles son las particularidades en el cambio de este paradigma en cuanto a su difusión en internet y las necesidades de regulación que ha generado, por lo que, finalmente, analizaremos dos formas de regulación: la primera en la sede interamericana y la segunda, en cuanto a la autorregulación comprendida en las normas comunitarias de Facebook, la red social elegida para esta investigación.

Finalmente, proponemos recomendaciones a nivel supranacional necesarias para brindar un margen adecuado a fin de que, cuando sea el Estado quien deba regular la protección de los derechos de las otras personas, no consiga desnaturalizar el derecho o el medio en ese proceso $\mathrm{y}$, en cuanto a las empresas, autorregular el contenido que mediante ellas se difunde. Todo ello con la intención de garantizar espacios de verdadera libertad preservando la esencia del derecho.

\section{LIBERTAD DE EXPRESIÓN}

\section{Antecedentes históricos}

Actualmente, el derecho a la libertad de expresión es considerado la piedra angular para la existencia misma de una sociedad democrática ${ }^{2}$; sin embargo, no siempre fue

2 CIDH. Informe Anual 2009. Informe de la Relatoría Especial para la Libertad de Expresión. Capítulo III (Marco jurídico interamericano del derecho a la libertad de expresión). OEA/ Ser.L/V/II. Doc. 51. 30 de diciembre de 2009. Párr. 8; Corte IDH. La Colegiación Obligatoria de Periodistas (arts. $13^{\circ}$ y 29. de la Convención Americana sobre Derechos Humanos). Opinión Consultiva OC-5/85 del 13 de noviembre de 1985 . Serie A No. 5. Párr. 70; Corte IDH. Caso Claude Reyes y otros Vs. Chile. Fondo, Reparaciones y Costas. Sentencia de 19 de septiembre de 2006. Serie C No. 151. Párr. 85; Corte IDH. Caso Herrera Ulloa Vs. Costa Rica. Excepciones Preliminares, Fondo, Reparaciones y Costas. Sentencia de 2 de julio de 2004. Serie C No. 107. Párr. 112; Corte IDH. Caso Ricardo Canese Vs. Paraguay. Fondo, Reparaciones así. Por ello, nos referiremos brevemente al origen histórico-normativo de este derecho para entender su contexto y sus implicancias actuales.

Al respecto, en Inglaterra encontramos que el artículo IX de Bill of Rights del 12 de febrero de 1689 señalaba:

Que las libertades de expresión, discusión y actuación en el Parlamento no pueden ser juzgadas ni investigadas por otro Tribunal que el Parlamento. ${ }^{3}$

En los Estados Unidos de América, encontramos como principal incorporación normativa en materia de libertad de expresión: la Primera Enmienda de la Constitución Federal de los Estados Unidos, aprobada el 15 de diciembre de 1791, conocida también como Bill of Rights, la cual establece que:

El Congreso no hará ley alguna por la que adopte una religión como oficial del Estado o se prohiba practicarla libremente, o que coarte la libertad de palabra o de imprenta, el derecho del pueblo para reunirse pacíficamente $y$ para pedir al Gobierno la reparación de agravios. $^{4}$

En Francia, encontramos el antecedente por excelencia de este derecho, luego de la revolución de 1789 , en el artículo $11^{\circ}$ de la Declaración de los Derechos del Hombre y del Ciudadano al reconocer que:

La libre comunicación de pensamientos y opiniones es uno de los derechos más valiosos del hombre; por consiguiente, cualquier ciudadano puede hablar, escribir e imprimir libremente, siempre y cuando responda del abuso de esta libertad en los casos determinados por la ley.

En España, el artículo $371^{\circ}$ de la Constitución de 1812 señalaba que:

y Costas. Sentencia de 31 de agosto de 2004. Serie C No. 111. Párr. 82; Corte IDH. Caso Ríos y otros Vs. Venezuela. Excepciones Preliminares, Fondo, Reparaciones y Costas. Sentencia de 28 de enero de 2009. Serie C No. 194. Párr. 105; Corte IDH. Caso Perozo y otros Vs. Venezuela. Excepciones Preliminares, Fondo, Reparaciones y Costas. Sentencia de 28 de enero de 2009. Serie C No. 195. Párr. 116.

3 Revise la traducción en: http://jorgemachicado.blogspot. com/2010/07/bor.html Texto original: http://avalon.law. yale.edu/17th_century/england.asp

4 Consulte el texto completo en: http://www.ieslasmusas.org/ geohistoria/derechos 1791.pdf 
Todos los españoles tienen libertad de escribir, imprimir y publicar sus ideas politicas sin necesidad de licencia, revisión o aprobación alguna anterior a la publicación, bajo las restricciones y responsabilidad que establezcan las leyes. ${ }^{5}$

Es relevante destacar que, en nuestro país, la Constitución de Cádiz anteriormente señalada fue aplicada también en nuestro territorio, en la época virreinal, por lo que constituye nuestro primer antecedente constitucional sobre la libertad de expresión. Sin embargo, la Constitución de 1826 en su artículo $143^{\circ}$ incorporó por primera vez en nuestro cuerpo constitucional naciente lo siguiente:

\section{Todos pueden comunicar sus pensamientos de palabra o por escrito, y publicarlos por medio de la imprenta sin censura previa, pero bajo la responsabilidad que la ley determine. $^{6}$}

Como se puede colegir, el derecho a la libertad de expresión surge como producto de los cambios ocurridos en el mundo a lo largo de las décadas, la Revolución francesa, la Revolución Industrial, la liberal española, entre otras, consiguieron, en primer término, que los ciudadanos sintieran la titularidad de sus derechos y el cambio de paradigma en relación con su función en la sociedad, no solo como miembros pasivos de la misma, sino como protagonistas del cambio, por lo que se hizo indispensable ampliar el concepto de libertad, que antes se asociaba únicamente a libertad personal o de tránsito, hacia uno que comprendiera la libertad de pensamiento que tiene su máxima expresión en la libertad de expresión, dejando de lado la visión individualista y unilateral del derecho a la libertad a la que se refería FernándezMiranda (1984). Así que históricamente se consideró que el rol del Estado era solo censurador, al haber sido el principal enemigo de las libertades; sin embargo, actualmente, se entiende que tiene un doble rol: en primer lugar, el de garantizar que las ideas y expresiones puedan ser manifestadas en la esfera democrática así como el de respetar este derecho, con lo que debe abstenerse de interferir con esta libertad, salvo situaciones

5 Consulte el texto completo en: http://www.congreso.es/ constitucion/ficheros/historicas/cons_1812.pdf

6 Consulte el texto completo en: http://www4.congreso.gob. pe/historico/quipu/constitu/1826.htm específicas que analizaremos más adelante, dentro de los límites de la libertad de expresión.

En segundo lugar, hacer visible y necesaria la evolución de los medios empleados para su difusión como elementos indispensables para el funcionamiento de la sociedad democrática y plural. Por ejemplo, el expresidente de los Estados Unidos en 1787, Thomas Jefferson, señalaba la importancia de los periódicos para la existencia de un gobierno eficaz, ${ }^{7}$ en donde todas las personas estén en la capacidad de conocer lo que ocurre en la sociedad así como de emitir su opinión. Años después, el relator especial para la Libertad de Expresión de la OEA (2001) resaltó la obligación de los Estados de no obstaculizar el ejercicio de este derecho a través del uso de internet. ${ }^{8}$

Como se evidencia, existe un largo camino andado entre la impresión únicamente física hasta la utilización de los medios virtuales para la difusión de las ideas; sin embargo, el contenido esencial de este derecho no ha cambiado, por lo que en las líneas siguientes analizaremos cuáles son los alcances y los límites de este derecho, atendiendo a los medios que se utilicen para su difusión.

\section{La libertad de expresión en los instrumentos internacionales}

Para conocer el contenido esencial de este derecho, nos referiremos al marco normativo existente, debido a que, si bien este derecho se encuentra consagrado en el artículo $2^{\circ}$, inciso 4 de la Constitución Política del Perú, no es el único cuerpo normativo aplicable a nuestro país. Esto es porque el artículo $\mathrm{V}$ del título preliminar del código procesal constitucional peruano señala que los derechos protegidos en la esfera constitucional se deben interpretar conforme los tratados internacionales de los que Perú sea parte y la jurisprudencia de los tribunales internacionales cuya competencia se haya ratificado. Por ello, nos referiremos brevemente al marco internacional en materia de libertad de expresión:

El artículo 19. ${ }^{\circ}$ de la Declaración Universal de Derechos Humanos señala que:

\footnotetext{
7 Consulte el texto original de la cita en: http://oll.libertyfund. org/quote/302

8 Consulte todo el documento en: http://www.oas.org/es/
} cidh/expresion/showarticle. asp? artID $=48 \&$ IID $=2$ 
Todo individuo tiene derecho a la libertad de opinión y de expresión; este derecho incluye el de no ser molestado a causa de sus opiniones, el de investigar y recibir informaciones y opiniones, y el de difundirlas, sin limitación de fronteras, por cualquier medio de expresión.

En cuanto a los límites de este derecho, el artículo $29^{\circ}$ de la Declaración establece que:

2. En el ejercicio de sus derechos y en el disfrute de sus libertades, toda persona estará solamente sujeta a las limitaciones establecidas por la ley con el único fin de asegurar el reconocimiento y el respeto de los derechos y libertades de los demás, y de satisfacer las justas exigencias de la moral, del orden público y del bienestar general en una sociedad democrática.

3. Estos derechos y libertades no podrán en ningún caso ser ejercidos en oposición a los propósitos y principios de las Naciones Unidas.

El artículo $13^{\circ}$ de la Convención Americana sobre Derechos Humanos señala que:

1. Toda persona tiene derecho a la libertad de pensamiento y de expresión. Este derecho comprende la libertad de buscar, recibir y difundir informaciones e ideas de toda índole, sin consideración de fronteras, ya sea oralmente, por escrito, en forma impresa o artística, o por cualquier otro procedimiento de su elección.

2. El ejercicio del derecho previsto en el inciso precedente no puede estar sujeto a previa censura, sino a responsabilidades ulteriores, las que deben estar expresamente fijadas por la ley y ser necesarias para asegurar:

a. El respeto a los derechos o a la reputación de los demás, o

b. La protección de la seguridad nacional, el orden público o la salud o la moral públicas.

3. No se puede restringir el derecho de expresión por vías o medios indirectos, tales como el abuso de controles oficiales o particulares de papel para periódicos, de frecuencias radioeléctricas, o de enseres y aparatos usados en la difusión de información o por cualesquiera otros medios encaminados a impedir la comunicación y la circulación de ideas y opiniones.

4. Los espectáculos públicos pueden ser sometidos por la ley a censura previa con el exclusivo objeto de regular el acceso a ellos para la protección moral de la infancia y la adolescencia, sin perjuicio de lo establecido en el inciso 2.

5. Estará prohibida por la ley toda propaganda en favor de la guerra y toda apología del odio nacional, racial o religioso que constituya incitaciones a la violencia o cualquier otra acción ilegal similar contra cualquier persona o grupo de personas, por ningún motivo, inclusive los de raza, color, religión, idioma u origen nacional.

El artículo IV de la Declaración Americana de los Derechos y Deberes del Hombre garantiza que:

Toda persona tiene derecho a la libertad de investigación, de opinión y de expresión $y$ difusión del pensamiento por cualquier medio.

Con la finalidad de ilustrar los estándares en el ámbito del sistema europeo, el artículo $10^{\circ}$ de la convención europea para la Protección de los Derechos Humanos y las Libertades Fundamentales reconoce que:

1. Toda persona tiene derecho a la libertad de expresión. Este derecho comprende la libertad de opinión y la libertad de recibir o de comunicar informaciones o ideas sin que pueda haber injerencia de autoridades públicas y sin consideración de fronteras. $E l$ presente artículo no impide que los Estados sometan a las empresas de radiodifusión, de cinematografía o de televisión a un régimen de autorización previa.

2. El ejercicio de estas libertades, que entrañan deberes y responsabilidades, podrá ser sometido a ciertas formalidades, condiciones, restricciones o sanciones, previstas por la ley, que constituyan medidas necesarias, en una sociedad democrática, para la seguridad nacional, la integridad territorial o la seguridad pública, la defensa del orden y la prevención del delito, la protección de la salud o de la moral, la protección de la reputación o de los derechos 
ajenos, para impedir la divulgación de informaciones confidenciales o para garantizar la autoridad y la imparcialidad del poder judicial.

Como se ha podido apreciar, en el Sistema Internacional existen conceptos claves así como lineamientos específicos en cuanto a concepto, límites y responsabilidades ulteriores que deben seguir los Estados para garantizar el ejercicio legítimo de este derecho sin afectar otros que existen en una sociedad democrática. Debido a ello, a continuación analizaremos estos estándares.

\section{La libertad de expresión en el Sistema Interamericano}

Estándar democrático y doble dimensión de este derecho en la jurisprudencia de la Corte Interamericana de Derechos Humanos

En el Sistema Interamericano, el primer antecedente del desarrollo de este derecho es la opinión consultiva $5 / 85$ de la Corte Interamericana de Derechos Humanos, cuando se consultó si exigir la colegiatura obligatoria para que los periodistas pudieran ejercer su trabajo en Costa Rica era violatorio de derechos humanos. La Corte determinó que sí era una violación, toda vez que constituía una exigencia desproporcionada para el ejercicio legítimo del derecho dentro del marco del «estándar democrático» y entendiendo la libertad de expresión dentro de este último como «una condición indispensable para que la comunidad, a la hora de ejercer sus opciones, esté suficientemente informada. Por ende, es posible afirmar que una sociedad que no esté bien informada no es plenamente libre» ${ }^{9}$. Estos criterios han sido afirmados en su jurisprudencia posterior.

Asimismo, acuñó el «estándar de las dos dimensiones» como referencia a este derecho, por lo que no debe vincularse únicamente con la dimensión individual del derecho, sino con la colectiva, las cuales deben ser garantizadas simultáneamente por el Estado de forma obligatoria.

En cuanto a la manifestación de la dimensión individual, el ejercicio de este derecho no

9 Corte IDH. La Colegiación Obligatoria de Periodistas (arts. $13^{\circ}$ y $29^{\circ}$ de la Convención Americana sobre Derechos Humanos). Opinión Consultiva OC-5/85 del 13 de noviembre de 1985. Serie A No. 5. Párr. 70 se encuentra satisfecho únicamente con la oportunidad de pensar, escribir o hablar, sino con la posibilidad de difundir estas ideas por cualquier medio apropiado, que pueda servir para que llegue a un número de destinatarios mucho mayor. En cuanto a la dimensión social o colectiva, se entiende así toda vez que permite que las ideas y pensamientos, sobre distintos temas tanto de coyuntura local como nacional, puedan ser intercambiados con los de otras personas y así poder enriquecer las opiniones y el sistema democrático, con la finalidad de garantizar que la sociedad esté verazmente informada. Así, queda demostrada la necesaria interacción entre ambas dimensiones, debido a que la posibilidad de pensar y transmitir las ideas propias como las de intercambiarlas con las demás personas tiene tanta importancia. Ello contribuye con el enriquecimiento social ${ }^{10}$ y crecimiento personal (Solózabal, 1991).

Finalmente, en cuanto al contenido esencialmente protegido por este derecho, es necesario enfatizar que este derecho no solo protege aquellas ideas que sean favorables para la mayoría y consideradas como inofensivas, sino también aquellas que «chocan, inquietan $\mathrm{u}$ ofenden al Estado o a una fracción cualquiera de la población», debido a que ello es garantía de un verdadero pluralismo, tolerancia y espíritu de apertura, sin las cuales no existe una «sociedad democrática» ${ }^{11}$. Así, el Estado está en la obligación de garantizar el ejercicio del derecho aún en las situaciones contrarias a sus intereses. Lo anterior podría generar la impresión de que existe un amplio margen que podría permitir el uso abusivo de este derecho; sin embargo, como veremos en los apartados siguientes, aquella conclusión resultaría apresurada debido a que existen límites claros para su ejercicio así como responsabilidades en caso de que se violen derechos de terceros.

\section{Prohibición de censura previa}

En el Sistema Interamericano se encuentra proscrita la censura previa, sin embargo, en el artículo 13.4 de la convención americana

10 Cfr. ibidem, párrs. 30-33

11 Corte IDH. Caso La Ultima Tentación de Cristo (Olmedo Bustos y otros) vs. Chile. Fondo, Reparaciones y Costas. Sentencia de 5 de febrero de 2001. Serie C No. 73, TEDH, caso Handyside, 7 December 1976, Series A No. 24, párr. 49; caso The Sunday Times, 26 April 1979, Series A no. 30, párrs. 59 y 65; Barthold judgment of 25 March 1985, Series A no. 90, párr. 55; Lingens judgment of 8 July 1986, Series A no. 103, párr. 41; Müller y otros, 24 May 1988, Series A no. 133, párr. 33; y OttoPreminger-Institut vs. Austria judgment of 20 September 1994, Series A no. 295-A, párr. 49 
se establece la única excepción a esta regla, siempre y cuando exista una limitación al acceso a espectáculos públicos. La Corte Interamericana tuvo la oportunidad de analizar un supuesto así cuando la CIDH sometió un caso bajo su jurisdicción contenciosa para que analice si el artículo $19^{\circ}$ inciso 12 de la Constitución chilena violaba el derecho a la libertad de expresión de los productores de la película La última tentación de Cristo, toda vez que había dado pie a que se negara el permiso de exhibirla en las salas de Chile por «cuestiones morales de la sociedad chilena». Dicho argumento fue rechazado por el Tribunal Interamericano, reafirmando que el único supuesto de censura se da cuando es necesaria la protección moral de la infancia y la adolescencia $^{12}$, lo que no ocurría en este caso, pues tenía claramente establecida la franja de edad para el público. Por ello, el Estado debió modificar su Constitución en pro de la libertad de expresión como parte de la adecuación del marco normativo en Chile, el cual actualmente tiene un desarrollo avanzado en materia de libertad de expresión e internet.

\section{Limites a la libertad de expresión y responsabilidades ulteriores}

Tal como señalábamos líneas arriba, podría parecer que en principio no existen límites para la libertad de expresión; sin embargo, el artículo 13.2 permite la aplicación de responsabilidades ulteriores al ejercicio de este derecho, con lo que garantiza la prohibición general de censura previa sin dejar de lado los derechos posiblemente afectados en el ejercicio abusivo e ilegal de esta libertad.

Atendiendo a ello, es necesario recordar lo establecido por la Corte Interamericana toda vez que su jurisprudencia ha sido clara en limitar la aplicación de los mecanismos de responsabilidad ulterior ante la presunta violación de los derechos de terceras personas como consecuencia del uso abusivo del derecho a la libertad de expresión, siempre y cuando sean medidas necesarias de adoptar en una sociedad democrática, es decir, que busquen satisfacer un interés público imperativo. Por ello, antes de aplicar una restricción a la libertad de expresión, deberá acudirse al examen de proporcionalidad (Bernal, 2007): en la etapa de idoneidad se

12 Corte IDH. Caso La última tentación de Cristo (Olmedo Bustos y otros) vs. Chile. Fondo, Reparaciones y Costas. Sentencia de 5 de febrero de 2001. Serie C No. 73, párr. 70. deberán verificar que la medida destinada a la restricción del derecho sea justificada por una necesidad colectiva; al analizar la idoneidad de la medida, se debe hacer un examen exhaustivo de mecanismos alternativos que puedan resultar menos lesivos al derecho que la medida analizada, y, finalmente, al analizar la proporcionalidad en sentido estricto, esta restricción debe ser proporcional al interés que la justifica y el logro del fin legítimo que se busca alcanzar, para que no limite el derecho más allá de lo estrictamente necesario.

A continuación, nos referimos a los mecanismos de responsabilidad ulterior analizados en el Sistema Interamericano que han sido recogidos por la legislación de los países de nuestra región. En ese sentido, el referido artículo 13.2 señala las situaciones en que se puede aplicar este tipo de responsabilidad posterior a la expresión de las ideas:

Cuando sean necesarias para asegurar el respeto a los derechos o a la reputación de los demás, o la protección de la seguridad nacional, el orden público o la salud o la moral públicas. Estas medidas deben estar señaladas claramente en la ley nacional.

En ese sentido, están comprendidos los delitos de difamación criminal (es decir, calumnias o injurias) y el delito de desacato. Sin embargo, por ser relevante para el desarrollo del artículo, nos referiremos solo a la primera de ellas.

\section{Delitos de difamación criminal}

El primer caso con el que la Corte Interamericana conoció este tipo de medidas fue el del señor Herrera Ulloa, periodista de La Nación de Costa Rica, quien fue sancionado por cometer cuatro delitos debido a la publicación de «ofensas en la modalidad de difamación» contra un funcionario público del Estado. La Corte analizó esta medida penal para determinar si había afectado el derecho a la libertad de expresión del periodista, más allá de que la legislación costarricense del momento permitiera la aplicación de dicha medida. En efecto, consideró que había pasado el umbral de lo permitido en el ámbito del estándar democrático anteriormente analizado, por lo que la aplicación de la medida penal al señor Ulloa había sido desproporcionada respecto del fin que se pretendía proteger. A raíz de este fallo, el Estado debió modificar su legislación. 
Asimismo, la Corte ha tenido la oportunidad de volverse a pronunciar sobre la posible afectación de los derechos de personajes públicos como, por ejemplo, en el caso del señor Ricardo Canese contra el Estado de Paraguay: la Corte ha afirmado que, a pesar de que estos funcionarios deben tener un mayor margen de tolerancia respecto de las afirmaciones que se hagan sobre ellos para permitir un debate amplio respecto a asuntos de interés público, como en el caso del señor Canese, toda vez que había sido sancionado penalmente en Paraguay por sus comentarios respecto de otro candidato a la presidencia, cuando ambos disputaban ese puesto. La Corte enfatizó la necesidad de que los derechos a la libertad de pensamiento y expresión, tanto en su dimensión individual como colectiva, se constituían en un «bastión fundamental» para fortalecer el debate durante el proceso electoral, necesario para que los electores puedan formar una opinión pública, así como una mayor transparencia y fiscalización en los comicios ${ }^{13}$. Por lo que, en el caso contra Paraguay, los tribunales paraguayos debieron tomar en consideración el contexto de campaña electoral en el cual se había producido las declaraciones, «ponderando el respeto a los derechos o a la reputación de los demás con el valor que tiene en una sociedad democrática el debate abierto sobre temas de interés o preocupación pública» ${ }^{14}$. Así que también se debió modificar la legislación para adecuarla al respeto de la libertad de expresión y garantizar la sociedad democrática.

Como se desprende de estos dos primeros casos en materia de libertad de expresión, la Corte falló analizando la existencia o no de la violación al derecho a la libertad de expresión, utilizando el principio de proporcionalidad, examinando la justa relación entre la medida adoptada, penal en estos casos, y la finalidad que se pretendía conseguir. La línea jurisprudencial de la Corte ha ido desarrollando los alcances de este derecho en diversos casos; sin embargo, lo fundado en estas sentencias sirve aún de fundamento para los venideros fallos. En ese sentido,

13 Corte IDH. Caso Ricardo Canese Vs. Paraguay. Fondo, Reparaciones y Costas. Sentencia de 31 de agosto de 2004 Serie C No. 111, párr. 71, Caso Herrera Ulloa vs. Costa Rica, supra nota 5, párrs. 128 y 129.

14 Corte IDH. Caso Ricardo Canese Vs. Paraguay. Fondo, Reparaciones y Costas. Sentencia de 31 de agosto de 2004. Serie C No. 111 párr. 105. consideramos que, con base en la propia Convención Americana y la jurisprudencia de la Corte, se debe entender que toda medida penal aplicada con responsabilidad ulterior no es per se violatoria de derechos humanos, así se trate de funcionarios públicos involucrados, sino que dependerá del análisis del caso en concreto, así como del razonamiento seguido por los tribunales en el ejercicio de ponderación.

\section{LIBERTAD DE EXPRESIÓN EN INTERNET}

Un ámbito gris dentro de la regulación de este derecho y al que nos dedicaremos a partir de aquí es el relativo a la libertad de expresión a través del internet y redes sociales. En los antecedentes de internet existe la Declaración de Independencia del Ciberespacio (1986) en el que se le ensalzaba como un ámbito de libertad absoluta sin ningún tipo de gobierno, ajeno a la jurisdicción de cualquier Estado y, por tanto, libre, donde todo debería autorregularse por los propios usuarios. ${ }^{15}$

Sin embargo, tal como analizábamos en las primeras líneas, al cambiar los canales de difusión de las ideas, conocimientos y opiniones, este derecho ha ido variando para adaptarse y esto ha significado un reto mayor para los Estados, que habían sido los únicos protagonistas de la regulación de este derecho hasta ese momento; sin embargo, ante la aparición de nuevas tecnologías, (Free Word Centre, 2013) las empresas intermediarias asumen un rol esencial en el ámbito de las nuevas tecnologías, tal como veremos en el siguiente capítulo, respecto a determinar los límites de este derecho, sin ir contra su contenido esencial. Es decir, internet no está libre de regulación, tal como consideraban en sus inicios, toda vez que a través de su uso se puede poner en riesgo derechos fundamentales y propiciar la comisión de delitos por lo que surge la necesidad de que el derecho intervenga como ente regulador (Goldsmith, 1998), al generarse un espacio social. Sin perjuicio de ello, se deben respetar sus propias singularidades para no desnaturalizarlo, por lo que no se puede aplicar directamente la regulación de cualquier otro medio de

15 Consulte el texto en: http://biblioweb.sindominio.net/ telematica/manif_barlow.html 
comunicación a internet, ya que se requiere un diseño especial y adecuado. ${ }^{16}$

Al respecto, el relator especial de las Naciones Unidas (2011) así como la relatora especial de la OEA han enfatizado que el derecho a la libertad de expresión, contenido en el artículo 13 de la Convención, se aplica plenamente al internet (Botero, 2013), debido a que ha facilitado a muchos ciudadanos expresarse libremente, así como ejercer derechos en línea, como el de la educación, por lo que fortalece la sociedad democrática, principio fundamental de este derecho, como desarrollábamos líneas supra. En razón a ello, existen diversas declaraciones que manifiestan el acuerdo de los Estados que resaltan la importancia de internet como medio de ejercicio de los derechos $\mathrm{y}$, especialmente, el de la libertad de expresión ${ }^{17}$; sin embargo,

16 Relatoría especial para la libertad de expresión de la Comisión Interamericana de Derechos Humanos. OEA/Ser.L/V/II CIDH/RELE/INF.11/13. Relator especial de las Naciones Unidas (ONU) sobre la promoción y protección del derecho a la libertad de opinión y de expresión, representante para la libertad de los medios de comunicación de la Organización para la Seguridad y la Cooperación en Europa (OSCE), relatora especial de la Organización de Estados Americanos (OEA) para la libertad de expresión, y relatora especial sobre libertad de expresión y acceso a la información de la Comisión Africana de Derechos Humanos y de los Pueblos (CADHP). 1 de junio de 2011. Declaración conjunta sobre libertad de expresión e internet. Punto 1 (c).

17 Relator especial de Naciones Unidas para la libertad de opinión y expresión (ONU), representante de la Organización de Seguridad y Cooperación en Europa para la libertad de los medios de comunicación (OSCE) y relator especial para la libertad de expresión (OEA). 20 de noviembre de 2001. Declaración conjunta sobre antiterrorismo, radiodifusión e internet; relator especial de la ONU sobre la libertad de opinión y expresión, representante de la OSCE sobre la libertad de prensa y relator especial de la OEA sobre libertad de expresión. 10 de diciembre de 2002. Declaración conjunta sobre libertad de expresión y administración de justicia, comercialización y libertad de expresión, y difamación penal; relator especial sobre la libertad de opinión y expresión de la ONU, representante sobre la libertad de prensa de la OSCE, relator especial sobre libertad de expresión de la OEA. 18 de diciembre de 2003. Declaración conjunta sobre la regulación de los medios, las restricciones a los periodistas y a la investigación de la corrupción; relator especial de las Naciones Unidas para la libertad de opinión y expresión, representante de la organización para la seguridad y cooperación en Europa para la libertad de los medios de comunicación y relator especial de la OEA para la libertad de expresión. 21 de diciembre de 2005. Declaración conjunta sobre internet y sobre medidas anti-terroristas; relator especial de las Naciones Unidas (ONU) para la libertad de opinión y de expresión, representante de la Organización para la Seguridad y la Cooperación en Europa (OSCE) para la libertad de los medios de comunicación, relatora especial de la Organización de Estados Americanos (OEA) para la libertad de expresión y relatora especial sobre libertad de expresión y acceso a la información de la Comisión Africana de Derechos Humanos y de los Pueblos (CADHP). 2 de febrero de 2010. Declaración conjunta del décimo aniversario: Diez desafios claves para la libertad de expresión en la próxima década; relator especial de las Naciones Unidas para la protección y promoción del derecho a la libertad de opinión y de expresión y relatora especial para la libertad de expresión de la comisión interamericana de derechos humanos. 21 de diciembre de 2010. Declaración conjunta sobre Wikileaks; relator especial de las Naciones Unidas (ONU) para la libertad hasta la actualidad no existe un tratado internacional que regule específicamente este derecho en internet aunque, como se ha evidenciado, se viene trabajando y discutiendo, a nivel de Naciones Unidas y la Organización de Estados Americanos, el entorno en línea y el ejercicio de los derechos humanos. ${ }^{18}$

\section{Regulación del contenido en internet}

En base a todo lo desarrollado anteriormente, queremos abordar finalmente dos formas de regulación del contenido del internet. Si bien a nivel europeo se pueden distinguir dos modelos específicos de regulación: el norteamericano y el europeo (Fernández, 1998, p. 88). Consideramos que puede contribuir a enriquecer el análisis referirnos a los parámetros con los que estamos directamente vinculados: el Estado, en el marco de la OEA, y lo ocurrido en redes sociales, específicamente, en Facebook. Por ello, dividiremos este capítulo para poder analizar ambos escenarios.

\section{Principios en el marco del Sistema Interamericano}

\section{Principios orientadores en el marco de la OEA}

La Relatoría Especial de la OEA para la Libertad de Expresión en el 2013 estableció cinco principios 19 que serán analizados a continuación para comprender el desarrollo ocurrido en la sede interamericana ante la ausencia de un marco orientador general y la necesidad de limitar las posibles violaciones en cuanto al acceso de este derecho en internet.

de opinión y de expresión, representante para la libertad de los medios de comunicación de la Organización para la Seguridad y la Cooperación en Europa (OSCE), relatora especial de la Organización de Estados Americanos (OEA) para la libertad de expresión y relatora especial sobre libertad de expresión y acceso a la información de la Comisión Africana de Derechos Humanos y de los Pueblos (CADHP). 1 de junio de 2011. Declaración conjunta sobre libertad de expresión e internet; relator especial de las Naciones Unidas (ONU) para la libertad de opinión y de expresión y relatora especial para la libertad de expresión de la comisión de derechos humanos de la OEA. 20 de enero de 2012. Declaración conjunta sobre libertad de expresión en internet del relator especial de las Naciones Unidas para la libertad de opinión y de expresión y la relatora especial para la libertad de expresión de la CIDH; relator especial de las Naciones Unidas (ONU) para la protección y promoción del derecho a la libertad de opinión y de expresión y relatora especial para la libertad de expresión de la Comisión Interamericana de Derechos Humanos de la OEA. 21 de junio de 2013. Declaración conjunta sobre programas de vigilancia y su impacto en la libertad de expresión.

18 Promoción, protección y disfrute de los derechos humanos en internet A/HRC/20/L.13 http://ap.ohchr.org/ documents/S/HRC/d_res_dec/A_HRC_20_L13.pdf

$19 \mathrm{CIDH}$. Libertad de expresión e internet. Relatoria Especial para la Libertad de Expresión. CIDH/RELE/INF. 11/13 31 diciembre 2013. 


\section{- Acceso}

De este principio se derivan las acciones para promover el acceso universal para su uso y calidad, a través de la eliminación de barreras tanto tecnológicas como de infraestructura, sin olvidar a los grupos especialmente vulnerables por diversas condiciones sociales. Es decir, garantizar «la conectividad y el acceso universal, ubicuo, equitativo, verdaderamente asequible y de calidad adecuada» en todo el territorio de cualquier Estado parte, para eliminar la brecha digital en el acceso a internet. (párrs. 15-17)

\section{- Pluralismo}

Es decir, debe generar que más personas tengan acceso al debate sobre lo que ocurre en la sociedad y la oportunidad de intercambiar sus opiniones pues constituye un elemento indispensable en el proceso democrático, que permite el acceso a la esfera pública, lo que antes era más difícil por la falta de medios adecuados. En ese sentido, tal como analizábamos, el Estado tiene el papel protagonista al garantizar el pluralismo informativo, la eliminación de barreras para el ejercicio al derecho a la libertad de expresión, toda vez que este derecho se ajusta perfectamente a lo comprendido en el artículo 13..$^{\circ}$ de la Convención Americana. (párrs. 18-19)

\section{- No discriminación}

Este principio, comprendido tanto en nuestro ordenamiento nacional como en el interamericano, impide que una persona o un grupo de personas pueda ser excluida del goce o ejercicio de sus derechos según raza, sexo, color y otras condiciones sociales, por lo que los Estados se encuentran en la obligación de adoptar todas las medidas adecuadas para que su aparato gubernamental impida la discriminación en el acceso a los derechos ${ }^{20}$, en este caso específico, el de la libertad de expresión en el entorno digital, con

20 CIDH. Informe anual 2008. Informe de la Relatoria Especial para la Libertad de Expresión. Capítulo III (Marco jurídico interamericano del derecho a la libertad de expresión). OEA/Ser. L/V/II.134. Doc 5 rev. 1. 25 de febrero de 2009. Párr. 230. Cfr. Propuesta de modificación a la Constitución Política de Costa Rica relacionada con la naturalización. Opinión consultiva OC-4/84 del 19 de enero de 1984 Serie A No. 4, párr 55, condición jurídica y derechos de los migrantes indocumentados. Opinión consultiva OC-18/03 del 17 de septiembre de 2003. Serie A No. 18, párr. 101 y caso comunidad indigena Xákmok Kásek. Vs. Paraguay. Fondo, Reparaciones y Costas. Sentencia de 24 de agosto de 2010 Serie C No. 214 , párr. 269. especial énfasis en permitir que estos grupos especialmente vulnerables vean impedido su derecho de manifestar su visión en asuntos de interés público basándose precisamente en su condición de vulnerabilidad histórica. (párrs. 20-21)

\section{- Privacidad}

Este principio obliga a los Estados a garantizar un espacio en línea protegido para que las personas puedan ejercer su derecho a la libertad de expresión sin el temor de que esta información sea difundida sin su consentimiento, ya que ello afectaría el ejercicio pleno de la comunicación y el sistema democrático, por lo que también se proscribe el monitoreo a la actividad en red (Cortés, 2013) así como la recopilación ilícita o arbitraria de los datos personales. Así, nuevamente se visibiliza el doble rol que deben cumplir los Estados en cuanto a abstenerse de impedir la comunicación libre, sin observaciones en la red y, por otro lado, de impedir que otras personas puedan actuar de forma abusiva contra los derechos de la persona escudándose en el entorno digital.

Consideramos que la vigencia de este principio no impide que no se pueda aplicar medidas de responsabilidad ulterior según el interés público, mencionado en el artículo 13.2 de la Convención Americana. Asimismo, la Asamblea General de las Naciones Unidas también ha reconocido la importancia de este principio en la era digital ${ }^{21}$.

\section{- Neutralidad de la red}

«Lo que persigue tal principio es que la libertad de acceso y elección de los usuarios de utilizar, enviar, recibir u ofrecer cualquier contenido, aplicación o servicio legal por medio de internet no esté condicionada, direccionada o restringida, por medio de bloqueo, filtración $\mathrm{o}$ interferencia» ${ }^{22}$.

21 Naciones Unidas. Asamblea General. Resolución aprobada por la Asamblea General el 18 de diciembre de 2013. 68/167. El derecho a la privacidad en la era digital. A/RES/68/167. 21 de enero de 2014. Párr. 4. Disponible para consulta en: http://www.un.org/Depts/dhl/resguide/r68_es.shtml

22 Relator especial de las Naciones Unidas sobre la promoción y protección del derecho a la libertad de opinión y expresión representante para la libertad de los medios de comunicación de la Organización para la Seguridad y la Cooperación en Europa (OSCE), relatora especial de la Organización de Estados Americanos (OEA) para la libertad de expresión, y relatora especial sobre libertad de expresión y acceso a la información de la Comisión Africana de Derechos Humanos y de los Pueblos (CADHP). 1 de junio de 2011. Declaración conjunta sobre libertad de expresión e internet. Punto 5 (a). 
Es decir, garantizar que el acceso a los contenidos sea igual a todas las personas para garantizar la discusión sobre los temas de coyuntura social.

\section{Las normas comunitarias de Facebook}

En relación con este punto, es importante recordar las teorías que inicialmente planteaban un universo sin control en internet, donde existiría un espacio propicio para la autorregulación. Lorenzo (2011) señala que, en las redes sociales, al ser las intermediarias que «alojan» el contenido de los usuarios, deben existir lineamientos específicos para evaluar el mensaje que se transmite pues podrían comprometer su propia responsabilidad en ciertas circunstancias. Abordaremos únicamente lo que sucede con Facebook y sus normas comunitarias, a la luz de todo lo anteriormente señalado respecto a la libertad de expresión.

Inicialmente en Facebook, cualquier persona podía crearse un perfil con información no necesariamente verdadera, y expresar sus opiniones e incluso trasgredir los derechos de los demás sin que existiera un medio de control efectivo. Si bien esa situación se sigue dando, lo cierto es que con la implementación de las normas comunitarias se intenta garantizar, en mayor medida, un espacio en línea donde se puede ver, en la práctica, los principios de la OEA que antes mencionábamos.

Así, cuando uno decide crearse una cuenta en Facebook, acepta los términos y condiciones de la plataforma, entre las que se encuentra las normas comunitarias a las que usualmente no se les presta la debida atención; sin embargo, cuando nos encontramos en situaciones que vulneran nuestros derechos, en la interacción con otros usuarios, resulta útil el análisis de las mismas, debido a que Facebook recibirá nuestra queja y la analizará en relación con las normas establecidas para la comunidad, lo que evidencia una falta de regulación específica en materia internacional.

Algunas situaciones comprendidas y sus consecuencias

- Amenazas directas

- Autolesiones

- Organizaciones peligrosas

- Acoso
- Ataques a personajes públicos

- Actividades delictivas

- Explotación y violencia sexual

- Desnudos

- Lenguaje que incita al odio

- Violencia y contenido gráfico

- Uso de la propiedad intelectual sin autorización.

- Fraude y spam

- Uso de la identidad de otras personas

Todas estas situaciones pueden ser denunciadas de forma anónima con la finalidad de brindar protección a los usuarios que pretendan evidenciar un contenido inapropiado en la red y las sanciones se aplicarán de acuerdo con el criterio de los administradores de Facebook, encargados de moderar su contenido. En buena cuenta, no existe una regulación mundial sobre lo expresado en las redes sociales, pero consideramos que los principios, características y límites a la libertad de expresión pueden ser perfectamente aplicados a esta plataforma, toda vez que, de no ser así, sería contradictorio al espacio creado en línea. En relación con ello, analizaremos lo siguiente:

\section{Grupos especialmente protegidos}

En cuanto a los grupos especialmente protegidos, si bien se parte de la idea de que la red social debe garantizar los derechos de todas las personas en general, se hace un especial énfasis en hostilidades producidas por raza, sexo, color, entre otras categorías especialmente protegidas. Por lo que si se demuestra que un perfil o fanpage está utilizando esta plataforma para ir en contra de personas pertenecientes a estos grupos, Facebook tiene la potestad de cerrar el perfil o página en cuestión.

Lo anterior lleva a plantearnos las siguientes preguntas: ¿Resultaría proporcional dicha medida ante una denuncia de este tipo? ¿No se estaría violando la libertad de expresión? En definitiva, siguiendo lo desarrollado en los capítulos anteriores, se concluiría que no, porque no se debe permitir un uso abusivo del derecho en general y, especialmente, cuando se trata de personas pertenecientes a categorías 
protegidas como las que señalamos, así que, bajo un examen de proporcionalidad de la medida, se podrían plantear supuestos menos lesivos, pero al estar en juego el principio de igualdad y ser considerado una norma de Ius Cogens ${ }^{23}$ (Cançado, 2007), no podría entrar al ámbito de estudio de proporcionalidad (Clérico, 2009).

\section{Cuentas falsas y regulación}

Una incorporación de estas normas comunitarias es la necesidad de verificar la relación con la información real del usuario de la red social. Así que, como parte de sus incorporaciones, pide la verificación de la cuenta a través del número de celular de la persona $\mathrm{y}$, si se trata de una empresa, de los documentos constitutivos de la misma. Además, cuando se quiere crear un fanpage, Facebook pide que se asocie a un perfil de Facebook auténtico, con la finalidad de poder asociar a la persona real tras un fanpage. Nuevamente, las sanciones pueden llegar hasta la eliminación de las cuentas.

\section{Vacíos}

Sin embargo, a pesar de estas normas comunitarias, sigue estando dentro de la discrecionalidad de la empresa cuándo aplicar sanciones ante las situaciones denunciadas y cuándo no, criterio que puede fallar en muchas ocasiones. Por ello, es necesario un marco normativo supranacional que brinde estándares claros y refleje la voluntad de los Estados en cuanto a los alcances de la libertad de expresión, y considere las garantías establecidas en la Convención Americana, específicamente en internet y redes sociales. Lo anterior guarda justa relación con el marco necesario dentro de un Estado democrático y los derechos de los demás miembros de la sociedad, que puedan ser vulnerados por encontrarse en esta zona gris, al menos en el estado actual de las cosas.

\section{CONCLUSIONES}

En primer lugar, en atención al origen histórico y al cambio que significó dejar de asociar la libertad únicamente con la libertad de tránsito, es importante mantener el contenido esencial del derecho a la libertad de expresión en internet, en su doble dimensión y en el

23 Corte IDH. Condición jurídica y derechos de los migrantes indocumentados. Opinión consultiva OC-18/03 de 17 de septiembre de 2003. Serie A No. 18, párrs. 97-101 y 110-111 marco del estándar democrático, en cuanto al desarrollo posterior del derecho en el Sistema Interamericano, al cual nos encontramos vinculados como Estado y cuyas decisiones influyen en nuestro ordenamiento nacional.

En segundo lugar, si bien este derecho representa la piedra angular de la democracia, no debe entenderse como absoluto (Tribunal Constitucional, $\mathrm{N}^{\mathrm{o}} 2465-2004-\mathrm{AA} / \mathrm{TC}$ ), por lo cual resulta importante resaltar la aplicación de responsabilidades ulteriores al ejercicio abusivo de este derecho. Aunado a ello, es importante el análisis de la proporcionalidad de la medida que se pretenda aplicar para guardar estricta relación con la finalidad que se busca resguardar en el marco de una sociedad democrática.

En tercer lugar, en cuanto al ejercicio de la libertad de expresión en internet, hemos podido verificar que los mismos estándares se aplican en la difusión de ideas y pensamientos por internet que por cualquier otra vía, siempre y cuando se garanticen las características especiales de este medio. En ese sentido, una persona no puede hacer un ejercicio abusivo del derecho amparándose en el anonimato de la red cuando pretenda o cometa violaciones a los derechos de terceros o de la sociedad.

En cuarto lugar, no debe interpretarse lo anterior como la exigencia de mayor severidad al analizar las expresiones vertidas por este medio, toda vez que esto implicaría la desnaturalización del derecho solamente por el medio empleado, lo cual no ocurre con la televisión, prensa escrita, radio, entre otros, debido a que se pretende proteger el núcleo esencial. Todo dependerá del cas d'espèce.

Finalmente, si bien es cierto existen estándares para el ejercicio de este derecho en internet, en el Sistema Interamericano las empresas intermediarias tienen un papel protagónico en cuanto a la regulación del contenido que soportan. Así, pudimos observar, en el caso de Facebook, la existencia de las normas comunitarias que buscan controlar las situaciones usuales de abuso del derecho y violación de privacidad, igualdad y demás derechos en red. Sin embargo, también podemos concluir que existen vacíos que se generan por la falta de un marco general de regulación de los derechos en red y las posibles sanciones que se deban aplicar cuando sucedan. 


\section{RECOMENDACIONES}

Atendiendo a lo concluido anteriormente, es necesaria la unificación de estándares generales en materia de internet a nivel supranacional, toda vez que eso permitirá reducir el amplio margen de discrecionalidad de las empresas intermediarias que permite actualmente que terceros puedan afectar los derechos de las demás personas en línea, impidiendo que los principios referidos en líneas supra puedan ser cumplidos a cabalidad.

Asimismo, a propósito de los avances que hemos podido evidenciar en el desarrollo de este trabajo, es necesario un análisis crítico en cuanto a la información vertida en línea y, específicamente, en Facebook. Por ejemplo, a pesar de que se prohíbe la creación de perfiles falsos, día a día podemos evidenciar que aquello no se cumple, toda vez que son empleados de distintas maneras. Seguramente en la República Popular China o en el Estado cubano sea necesario encriptar la información que se quiere transmitir por temor a las represalias del Gobierno así como el uso de perfiles falsos; sin embargo, en una sociedad democrática, como la de nuestro país, el Estado debe tener un rol de mayor garantía para permitir, por un lado, un entorno seguro en la red y, por otro, impedir que terceros sean capaces de agredir los derechos fundamentales de las personas a través de las redes sociales. Con lo anterior no pretendemos que exista una regulación que permita la censura previa, sino que se apliquen las responsabilidades ulteriores cuando sea adecuado, siguiendo los lineamientos antes desarrollados.

Para ello, es necesario un trabajo coordinado. Así como Facebook señala en sus normas comunitarias la facultad de poder presentar un caso de acoso o violación sexual a las autoridades del país en cuestión, también debe ser en doble vía, en tanto los Estados pueden y deben trabajar coordinadamente para que los reportes presentados ante la plataforma de Facebook estén conectados con los funcionarios especialistas a fin de seguir el trámite de acuerdo con la ley aplicable en el Estado.

Todoloanteriorpermitiráejercerverdaderamente los derechos en línea en libertad, ya que de lo contrario las personas vivirán con el temor de no encontrarse en un espacio social que ofrezca las garantías adecuadas para la protección de sus datos y derechos.

\section{REFERENCIAS BIBLIOGRÁFICAS}

\section{Jurisprudencia y Opiniones Consultivas de la Corte Interamericana de Derechos Humanos}

CIDH. Informe Anual (2009). Informe de la Relatoría Especial para la Libertad de Expresión. Capítulo III (Marco jurídico interamericano del derecho a la libertad de expresión). OEA/Ser.L/V/II. Doc. 51. 30 de diciembre de 2009.

Condición Jurídica y Derechos de los Migrantes Indocumentados. Opinión Consultiva OC18/03 del 17 de septiembre de 2003. Serie A No. 18, párr. 101.

Corte IDH. Caso «La Última Tentación de Cristo» (Olmedo Bustos y otros) vs. Chile. Fondo, Reparaciones y Costas. Sentencia de 5 de febrero de 2001. Serie C No. 73.

Corte IDH. Caso Claude Reyes y otros Vs. Chile. Fondo, Reparaciones y Costas. Sentencia de 19 de septiembre de 2006. Serie C No. 151.

Corte IDH. Caso de la Comunidad Indígena Xákmok Kásek. Vs. Paraguay. Fondo, Reparaciones y Costas. Sentencia de 24 de agosto de 2010 Serie C No. 214.

Corte IDH. Caso Herrera Ulloa Vs. Costa

Rica. Excepciones Preliminares, Fondo, Reparaciones y Costas. Sentencia de 2 de julio de 2004. Serie C No. 107.

Corte IDH. Caso Perozo y otros Vs. Venezuela. Excepciones Preliminares, Fondo, Reparaciones y Costas. Sentencia de 28 de enero de 2009. Serie C No. 195.

Corte IDH. Caso Ricardo Canese Vs. Paraguay. Fondo, Reparaciones y Costas. Sentencia de 31 de agosto de 2004. Serie C No. 111.

Corte IDH. Caso Ricardo Canese Vs. Paraguay. Fondo, Reparaciones y Costas. Sentencia de 31 de agosto de 2004. Serie C No. 111, párr. 71, Caso Herrera Ulloa vs. Costa Rica, supranota 5, párrs. 128 y 129.

Corte IDH. Caso Ricardo Canese Vs. Paraguay. Fondo, Reparaciones y Costas. Sentencia de 31 de agosto de 2004. Serie C No. 111 párr. 105. 
Corte IDH. Caso Ríos y otros Vs. Venezuela. Excepciones Preliminares, Fondo, Reparaciones y Costas. Sentencia de 28 de enero de 2009. Serie C No. 194.

Corte IDH. Condición Jurídica y Derechos de los Migrantes Indocumentados. Opinión Consultiva OC-18/03 de 17 de septiembre de 2003. Serie A No. 18.

Corte IDH. La Colegiación Obligatoria de Periodistas (arts. $13 .^{\circ}$ y $29 .^{\circ}$ de la Convención Americana sobre Derechos Humanos). Opinión Consultiva OC-5/85 del 13 de noviembre de 1985. Serie A No. 5.

\section{Jurisprudencia del Tribunal Europeo}

TEDH. Otto-Preminger-Institut vs. Austria judgment of 20 September 1994, Series A no. 295-A.

TEDH. Caso Handyside vs. Reino Unido, 7 December 1976, Series A no. 24.

TEDH. Caso The Sunday Times vs. Gran Bretaña, 26 de Abril de 1979, Series A no. 30.

TEDH Barthold vs. Alemania, 25 de Marzo de 1985, Series A no. 90, párr. 55.

TEDH. Lingens vs. Austria, 8 de Julio de 1986, Series A no. 103.

TEDH. Müller y otros vs. Suiza, 24 de Mayo de 1988, Series A no. 133.

\section{Doctrina}

Bernal, C. (2007). El principio de proporcionalidad y los derechos fundamentales. Centro de Estudios Políticos y Constitucionales: Madrid.

Botero, C. (2013). Relatoría Especial para la Libertad de Expresión de la Comisión Interamericana de Derechos Humanos. OEA/ Ser.L/V/II CIDH/RELE/INF.11/13.

Cançado, A. (2007). La ampliación del contenido material del Ius Cogens. XXXIV Curso Internacional de Derecho Internacional de la OEA.

CIDH. Informe Anual 2008. Informe de la Relatoría Especial para la Libertad de Expresión. Capítulo III (Marco jurídico interamericano del derecho a la libertad de expresión). OEA/Ser. L/V/II.134. Doc 5 rev. 1. 25 de febrero de 2009.
CIDH. Libertad de expresión e internet. Relatoría Especial para la Libertad de Expresión. CIDH/RELE/INF. 11/13 31 diciembre 2013.

CIDH. Libertad de expresión e internet. Relatoría Especial para la Libertad de Expresión. CIDH/RELE/INF. 11/13 31 diciembre 2013.

Clérico, L. (2009). El examen de proporcionalidad en el Derecho Constitucional ( $1^{\mathrm{a}}$ ed.). Ed. Eudeba: Buenos Aires.

Cortés C. (2013). Vigilancia de la red: ¿qué significa monitorear y detectar contenidos en internet? Centro de Estudios en Libertad de Expresión y Acceso a la Información (CELE), Buenos Aires.

Cotino, L. (2011). Libertades de expresión e información en internet y las redes sociales: ejercicio, amenazas y garantías. Servei de Publicacions de la Universitat de València.

Declaración conjunta del décimo aniversario: diez desafíos claves para la libertad de expresión en la próxima década; relator especial de las Naciones Unidas para la protección y promoción del derecho a la libertad de opinión y de expresión y relatora especial para la libertad de expresión de la Comisión Interamericana de Derechos Humanos. 21 de diciembre de 2010.

Declaración conjunta sobre la regulación de los medios, las restricciones a los periodistas y a la investigación de la corrupción; relator especial de las Naciones Unidas para la libertad de opinión y expresión, representante de la Organización para la Seguridad y Cooperación en Europa para la libertad de los medios de comunicación y relator especial de la OEA para la libertad de expresión. 21 de diciembre de 2005.

Declaración conjunta sobre libertad de expresión e internet; relator especial de las Naciones Unidas (ONU) para la libertad de opinión y de expresión y relatora especial para la libertad de expresión de la Comisión de Derechos Humanos de la OEA. 20 de enero de 2012.

Declaración Conjunta sobre libertad de expresión en internet del relator especial de las Naciones Unidas para la libertad de opinión y de expresión y la relatora especial para la 
libertad de expresión de la $\mathrm{CIDH}$; relator especial de las Naciones Unidas (ONU) para la protección y promoción del derecho a la libertad de opinión y de expresión y relatora especial para la libertad de expresión de la Comisión Interamericana de Derechos Humanos de la OEA. 21 de junio de 2013. Declaración conjunta sobre programas de vigilancia y su impacto en la libertad de expresión.

Declaración Conjunta sobre Wikileaks; relator especial de las Naciones Unidas (ONU) para la libertad de opinión y de expresión, representante para la libertad de los medios de comunicación de la organización para la seguridad y la cooperación en Europa (OSCE), Relatora especial de la Organización de Estados Americanos (OEA) para la libertad de expresión y relatora especial sobre libertad de expresión y acceso a la información de la Comisión Africana de Derechos Humanos y de los Pueblos (CADHP). 1 de junio de 2011.

Fernández, Ma. L. (1998). Nuevas tecnologías, Internet $y$ derechos fundamentales. Ed. Mc GrawHill: Madrid.

Fernández-Miranda, A. (1984). «Artículo 20. Libertad de expresión y derecho de la información». En Alzaga Villaamil, Comentarios a las Leyes politicas, Tomo II, Edersa, Madrid.

Free Word Centre. (2013). Article 19 intermediarios de internet: Disyuntiva por la atribución de responsabilidad civil y penal.

Goldsmith, J. (1998). «Against Cyberanarchy». En University of Chicago Law Review, Núm. 65. Recuperado de: http://groups.csail.mit.edu/ mac/classes/6.805/articles/goldsmith-againstcyberanarchy.html

\section{Informes y declaraciones de la OEA y ONU}

Mecanismos internacionales para la promoción de la libertad de expresión. Declaración Conjunta. Desafíos a la libertad de expresión en el nuevo siglo.

Naciones Unidas. Asamblea General. Informe del relator especial sobre la promoción y la protección del derecho a la libertad de opinión y de expresión. A/66/290. 10 de agosto de 2011. Párr. 61. Disponible en http://ap.ohchr. org/documents/dpage_s.aspx? $\mathrm{m}=85$.
Naciones Unidas. Asamblea General. Resolución aprobada por la Asamblea General el 18 de diciembre de 2013.68/167. El derecho a la privacidad en la era digital. A/RES/68/167. 21 de enero de 2014. Párr. 4. Disponible en: http://www.un.org/Depts/dhl/resguide/r68 es.shtml

Naciones Unidas. Consejo de Derechos Humanos. Promoción, protección y disfrute de los derechos humanos en internet. A/ HRC/20/L.13. 29 de junio de 2012.

Naciones Unidas. Promoción, protección $\mathrm{y}$ disfrute de los derechos humanos en Internet A/HRC/20/L.13 http://ap.ohchr.org/ documents/S/HRC/d_res_dec/A_HRC_20_ L13.pdf

Relator especial de la ONU sobre la libertad de opinión y expresión, representante de la OSCE sobre la libertad de prensa y relator especial de la OEA sobre libertad de expresión. 10 de diciembre de 2002.

Relator Especial de las Naciones Unidas (ONU) sobre la promoción y protección del derecho a la libertad de opinión y de expresión, representante para la libertad de los medios de comunicación de la Organización para la Seguridad y la Cooperación en Europa (OSCE), Relatora especial de la Organización de Estados Americanos (OEA) para la Libertad de Expresión

Relator especial sobre la libertad de opinión y expresión de la ONU, representante sobre la libertad de prensa de la OSCE, relator especial sobre libertad de expresión de la OEA. Declaración conjunta sobre libertad de expresión y administración de justicia, comercialización y libertad de expresión, y difamación penal. 18 de diciembre de 2003.

Relatora especial sobre libertad de expresión y acceso a la información de la Comisión Africana de Derechos Humanos y de los Pueblos (CADHP). 1 de junio de 2011.

Solozábal Echevarría, J. J. (1991). «La libertad de expresión desde la teoría de los derechos fundamentales». En Revista Española de Derecho Constitucional. 